\title{
O Caso default no português do Brasil: revisitando o Caso dos inacusativos
}

Evani Viotti

USP

\section{Abstract}

The goal of this paper is to investigate the contexts in Brazilian Portuguese in which DPs are marked with nominative default Case, and to analyse the possibility of attributing default Case to the DPs in post-verbal position of sentences built with inaccusative verbs. The claim is that, if the verb shows agreement features, such DPs will check the nominative Case in the syntax; if the verb is uninflected for person and number, such DPs will receive a default Case marking in the morphological component. 


\section{INTRODUÇÃO}

$\mathrm{E}$

ste trabalho tem por objetivo investigar os contextos do português brasileiro em que DPs ${ }^{1}$ são marcados com o Caso default, e analisar a possibilidade de se atribuir esse tipo de Caso aos DPs em posição pós-verbal das sentenças construídas com verbos inacusativos, como em (1):

(1) a) Chegaram várias pessoas na festa.

b) Chegou várias pessoas na festa.

Como se sabe, no âmbito da Gramática Gerativa, verbos inacusativos têm sido considerados incapazes de atribuir Caso a seu único argumento. Considerando-se que sentenças como as em (1) são gramaticais, esses argumentos devem receber Caso de alguma outra forma. Várias propostas têm buscado solucionar essa questão. Dentro do modelo de Regência e Ligação, destacam-se as hipóteses de Chomsky (1981, 1986), baseadas em Burzio (1986), e a de Belletti ${ }^{2}$ (1988). O Programa Minimalista (CHOMSKY, 1995, 1998, 1999) adapta as idéias de Chomsky $(1981,1986)$ ao novo modelo de gramática proposto. Neste artigo, na esteira de trabalhos anteriores (VIOTTI, 1999, 2003a, b) e partindo da hipótese sobre o Caso default de Schütze (2002), sugiro que o Caso do argumento de verbos inacusativos é sempre o nominativo. Entretanto, existe uma diferença entre o Caso nominativo das sentenças em (1)a e (1)b. Em uma sentença como (1)a, em que o verbo apresenta marcas de concordância com seu único argumento, o Caso nominativo é licenciado na sintaxe. Diferentemente, em uma sentença como (1)b, em que o verbo não exibe marcas de concordância com seu argumento, trata-se do Caso 
nominativo default, atribuído ao DP no componente morfológico. Como vai ser visto adiante, a configuração sintática das sentenças construídas com verbos inacusativos sem concordância é um dos contextos em que se justifica a postulação do Caso default.

No item 2, apresento as idéias de Schütze sobre o Caso default. No item 3, analiso vários contextos do português do Brasil em que o Caso nominativo apresentado por DPs só pode ser considerado um Caso default. No item 4, concentro-me na análise do Caso do argumento dos verbos inacusativos.

\section{O CASO DEFAULT SEGUNDO SCHÜTZE (2002)}

\subsection{1 que é o Caso default}

A noção de Caso default de Schütze se baseia na idéia, contrária à que era assumida no modelo de Regência e Ligação, de que é necessário tratar licenciamento sintático de Caso e marcação morfológica de Caso separadamente. Para Schütze, trata-se de processos diversos, associados a sistemas diferentes.

A proposta de Schütze se vale, crucialmente, da idéia que vem sendo explorada no âmbito da Morfologia Distribuída de Halle \& Marantz (1993), segundo a qual existe um componente morfológico pós-spell-out, no qual a inserção do vocabulário é feita. Para ele, a marcação morfológica de Caso sempre se dá no componente morfológico. Entretanto, alguns sintagmas nominais têm sua flexão de Caso determinada pela sintaxe. Outros, não. Estes últimos chegam ao componente morfológico sem nenhuma indicação sobre a forma de Caso com a qual devem ser foneticamente realizados. Nesse caso, a morfologia atribui a eles a forma do Caso default. Portanto, nos termos de Schütze, o Caso default não tem nenhum papel no licenciamento de DPs na sintaxe, nem é conseqüência de algum tipo de licenciamento sintático de Caso. Ao contrário, as formas de Caso default de uma língua são aquelas usadas para a realização de sintagmas nominais que não são associados a nenhum traço de Caso a eles atribuído ou checado por mecanismos sintáticos. 
Em outros termos, um sintagma nominal pode entrar na derivação sintática de duas maneiras: (i) com traços de Caso nominativo, acusativo, etc., ou (ii) sem nenhum traço de Caso. Aqueles que apresentam traços de Caso ao entrarem na derivação sintática precisam ter esses traços checados ou na sintaxe aberta, ou na Forma Lógica, uma vez que são traços [-interpretáveis]. ${ }^{3}$ Ao chegarem ao componente morfológico, esses sintagmas nominais recebem as marcas morfológicas de Caso que são condizentes com o licenciamento sintático de Caso que eles tiveram: as marcas vão ser de Caso nominativo, se a checagem dos traços de Caso tiver sido feita em Spec TP; as marcas vão ser de Caso acusativo, se a checagem tiver sido feita na projeção de $v \mathrm{P}$; e assim por diante. No que diz respeito aos sintagmas nominais que entram na derivação sem traços de Caso, na sintaxe, nada acontece a eles relativamente a Caso. Mesmo assim, eles sobrevivem até LF, porque não têm traços [-interpretáveis] que precisem ser checados e apagados na sintaxe. No componente morfológico, eles recebem as marcas morfológicas do Caso default da língua em questão. Schütze enfatiza que Caso default não é Caso atribuído por um constituinte a outro. Ele é usado exclusivamente para realizar morfo-fonologicamente um nó terminal de uma árvore sintática, sendo totalmente invisível para a sintaxe.

Duas conseqüências dessa proposta são particularmente importantes. Primeiramente, o licenciamento de Caso na sintaxe não pode ser motivado por razões morfo-fonológicas. Afinal, um sintagma nominal pode entrar na derivação sem Caso e passar incólume pela sintaxe, sem que isso cause a não-convergência da derivação. Em segundo lugar, o Caso default não pode salvar uma derivação sintática que não tenha convergido por falta da checagem de traços de Caso. Se isso fosse possível, todo o sistema de licenciamento de Caso na sintaxe seria inútil. Desse modo, o Caso morfológico não pode ser visto nem como uma condição necessária nem como uma condição suficiente para satisfazer a necessidade do licenciamento sintático de Caso. Como mostra Schütze, embora em inglês haja um Caso default acusativo, sentenças como as em (2), 
cuja agramaticalidade se deve à violação do licenciamento sintático de Caso, continuam agramaticais mesmo com a marca morfológica de Caso acusativo.

(2) a) *It seems him/he to be tired.

b) *It is important he/him to be on time.

c) *Me, I, Tuesday is fine.

\subsection{Como sintagmas nominais recebem marcas morfológicas de Caso}

Nos termos do modelo de Schütze, os seguintes processos sintáticos autorizam o componente morfológico a atribuir uma determinada marca de Caso a um DP:

(i) a atribuição de Caso a um DP por um núcleo, como Infl ou um verbo;

(ii) a correspondência entre um DP e um outro constituinte a ele semanticamente relacionado (um DP deslocado à esquerda pode ter as mesmas marcas de Caso do argumento que lhe corresponde);

(iii) o espalhamento do Caso de um núcleo para outros constituintes dentro de sua projeção (em latim, por exemplo, existe concordância nas marcas de Caso entre um nome e os adjetivos que aparecem dentro do mesmo sintagma nominal);

(iv) o Caso semântico (em várias línguas que têm um sistema rico de marcação de Caso, DPs podem ter funções adverbiais, cujo sentido particular depende da escolha do Caso - por exemplo, dativo para duração, ablativo para instrumento, e assim por diante).

Uma vez que o DP tenha tido seu Caso licenciado na sintaxe por um desses mecanismos, a morfologia vai saber qual a flexão de Caso que a ele deve ser atribuída. As marcas de Caso default só vão ser atribuídas a um DP se nenhum dos mecanismos elencados entre (i) e (iv) tiver sido aplicado. Portanto, para se identificarem os DPs com Caso default, é necessário encontrar os contextos em que 
nenhum dos mecanismos sintáticos se aplica. A seguir, identificamos esses contextos no português do Brasil.

\section{O CASO DEFAULT EM PORTUGUÊS BRASILEIRO}

Como se sabe, em português brasileiro, de maneira geral, os DPs não recebem marcas morfológicas de Caso. A única exceção fica por conta do paradigma pronominal, que diferencia as formas do nominativo, do acusativo e do oblíquo. Imaginemos que feixes de traços de pronome da $1^{\mathfrak{a}}$ pessoa do singular entrem na derivação sintática acompanhados de traços de Caso. Esses traços vão precisar ser checados na sintaxe. Como já dito, se os traços forem checados em Spec TP, a realização morfo-fonológica do conjunto de traços pronominais de $1^{a}$ pessoa do singular vai corresponder à forma nominativa $e u$; se, por outro lado, esses traços forem checados em $v \mathrm{P}$, a realização morfo-fonológica do conjunto de traços pronominais vai corresponder à forma acusativa me; e assim por diante.

Neste item, examino alguns contextos do português, em que pronomes aparecem inesperadamente na forma nominativa, uma vez que eles não estão em posição de Spec TP, nem estão associados a um outro DP da sentença marcado com Caso nominativo. ${ }^{4}$ Como vamos ver, em nenhum desses contextos ocorre qualquer um dos tipos de licenciamento sintático de Caso apontados no item 2.2. Isso indica que a marca de Caso nominativo que esses pronomes apresentam deve ser uma instância do Caso default do português brasileiro.

\subsection{Deslocamentos}

Consideremos os seguintes exemplos:

(3) Eu, o João gosta de me encontrar.

(4) O jornalista entrevistou a única professora disponível, eu.

As sentenças em (3) e (4) são construções que têm sido chamadas de deslocamento à esquerda e deslocamento à direita, respectivamente. 
Normalmente, essas construções têm sido analisadas como conseqüência de uma adjunção na base, e não de um movimento. ${ }^{5}$ Considera-se que os pronomes nominativos assinalados em negrito estão em uma posição não-argumental, na qual eles foram gerados. Assim sendo, eles não estão em uma posição sintática em que há qualquer licenciamento sintático de Caso. Como também acredita-se que eles tenham sido gerados nessa posição e não movidos até ela, eles não podem ter passado por uma posição sintática em que Caso pudesse ter sido licenciado. Além disso, nas duas sentenças, o pronome marcado com a forma nominativa está semântica e referencialmente associado a um outro DP da mesma sentença, marcado com Caso acusativo: o clítico me, em (3), e o DP a única professora disponível, em (4). ${ }^{6}$ Portanto, devemos estar diante de um DP marcado com Caso default e temos uma forte evidência de que o Caso default em português do Brasil é o nominativo.

Seria possível levantar-se a objeção de que o pronome acusativo, em português, é um clítico, e, como tal, jamais poderia aparecer em uma posição em que não estivesse cliticizado ao verbo. Essa poderia ser a razão da agramaticalidade das seguintes sentenças:

(5) *Me, o João gosta de me encontrar.

(6) *O jornalista entrevistou a única professora disponível, me.

Entretanto, temos também pronomes marcados com o Caso oblíquo que não são clíticos. E eles tampouco podem substituir os pronomes nominativos das sentenças (3) e (4):

(7) *Mim, o João gosta de me encontrar.

(8) *O jornalista entrevistou a única professora disponível, mim.

Isso nos dá uma outra forte indicação de que o Caso default do português brasileiro é o Caso nominativo.

\subsection{Elipse}

Em enunciados elípticos, em que não há nenhum núcleo atribuidor de Caso, como Infl ou o verbo, os pronomes são marcados com a forma nominativa, mesmo quando eles correspondem ao 
complemento de um verbo que, em geral, recebe marcas de Caso acusativo. Assim, a uma pergunta como Quem o João gosta de encontrar?, poderíamos dar as seguintes respostas:

(9) a) Eu.

b) Só eu.

c) Eu não.

Ou ainda, para complementar uma sentença como O médico vai examinar a Maria, poderíamos ter os seguintes enunciados:

(10) a) E eu também.

b) E eu a seguir.

Isso também se verifica em outros casos de elipses, como (11):

(11) Quem o jornalista pode entrevistar, senão eu?

Em todos esses exemplos, o pronome nominativo eu corresponde ao complemento de um verbo, que deveria ter marcas de Caso acusativo, caso seu licenciamento tivesse ocorrido na sintaxe. O fato de o pronome ter marcas de nominativo e não de acusativo é mais uma evidência de que estamos diante de um contexto em que não existe licenciamento sintático de Caso. É justamente em contextos desse tipo que o Caso default se aplica.

\subsection{Gapping}

Em alguns contextos em que o verbo foi elidido da segunda oração, o constituinte que corresponde ao objeto direto pronominal aparece na forma nominativa, contrariamente ao esperado, como mostram os seguintes exemplos:

(12) Eu não suporto o João e ele eu.

(13) Por que o Pedro não pode levar a Ana na festa e o Ricardo eu?

(14) Quem os meninos encontraram? O João a Maria, o Pedro a Ana, e o Rui eu.

(15) O Pedro conheceu a Ana no Rio, eu em Salvador. 
Nesses exemplos, o pronome objeto direto marcado com nominativo aparece em um contexto em que o verbo, natural atribuidor de Caso acusativo, não aparece. Notem que, qualquer que seja a hipótese sobre a elisão do verbo - seja ela decorrente do fato de o verbo não ser um constituinte da segunda oração, seja ela decorrente da possibilidade de o verbo não ter sido pronunciado -, não existe uma explicação para que o pronome apareça na forma nominativa, a não ser que se postule o Caso default. Notem, também, que, como em todos os demais casos de ocorrência do Caso default, a forma tônica oblíqua não é possível, sem que ela esteja no contexto de um atribuidor de Caso, como uma preposição. Assim, uma versão mais formal das sentenças entre (12) e (15) seriam as sentenças entre (16) e (19), em que a preposição estaria atribuindo o Caso oblíquo ao pronome:

(16) Eu não suporto o João e ele a mim.

(17) Por que o Pedro não pode levar a Ana na festa e o Ricardo a mim?

(18) Quem os meninos encontraram? O João a Maria, o Pedro a Ana, e o Rui a mim.

(19) O Pedro encontrou a Ana no Rio, a mim em Salvador.

\subsection{Coordenação}

Consideremos os seguintes exemplos:

(20) a) O jornalista entrevistou uma professora de História e eu.

b) O jornalista entrevistou eu e uma professora de História.

b) *O jornalista entrevistou-me e uma professora de História.

c) *O jornalista me entrevistou e uma professora de História.

Esses casos são particularmente interessantes, na medida em que o constituinte coordenado está em um contexto em que a atribuição de Caso acusativo pelo verbo deveria acontecer. Entretanto, como Schütze aponta, a coordenação parece ser um contexto de Caso 
default em várias línguas. Notem que, em inglês, que tem o Caso default acusativo, em sintagmas coordenados em posição de sujeito, na fala coloquial, os pronomes aparecem na forma acusativa:

(21) Us and them are gonna rumble tonight.

(22) Her and us have been friends for ages.

Nesses casos, assume-se que os sintagmas coordenados estão na posição de Spec TP, em que Caso nominativo é licenciado. Portanto, seria de se esperar que as formas em (21) e (22) fossem agramaticais, contrariamente aos fatos. ${ }^{7}$

Uma outra evidência para isso, que o português do Brasil fornece, são os casos de constituintes coordenados sob uma preposição, em que deveríamos ter o Caso oblíquo (como prescreve a gramática normativa), mas em que, de maneira geral, preferimos o Caso nominativo, como mostram os exemplos a seguir:

(23) a) A discussão é entre ele e eu.

b) A discussão é entre eu e ele.

c) *A discussão é entre mim e ele. ${ }^{8}$

d) *A discussão é entre ele e mim.

(24) a) A discussão é entre tu e eu. ${ }^{?}$

b) A discussão é entre eu e tu.

c) *A discussão é entre mim e ti.

d) *A discussão é entre ti e mim.

Essa ocorrência também se verifica em espanhol. Pronomes coordenados complementos de algumas preposições aparecem na forma nominativa, diferentemente de pronomes complementos de preposição não-coordenados, que aparecem na forma oblíqua:

(25) a) Hicimos el trabajo entre tú y yo.

b) *Hicimos el trabajo entre ti y mi.

c) Hicimos el trabajo para ti.

d) *Hicimos el trabajo para tu. ${ }^{10}$ 
Uma possibilidade de explicação que vejo para esses fatos é a de que o licenciamento sintático de Caso acontece em relação ao sintagma coordenado como um todo. Portanto, é o núcleo do sintagma coordenado $\left(\&^{0}\right)$ que recebe Caso nominativo de Infl (exemplos do inglês), Caso acusativo do verbo (exemplos do português), e Caso oblíquo da preposição (exemplos do português e de espanhol). Por alguma razão, esse Caso não pode ser espalhado para os constituintes que fazem parte da projeção coordenada. Desse modo, o interior de um sintagma coordenado torna-se um contexto de Caso default. De qualquer maneira, essa é uma questão que requer uma análise mais aprofundada e não pode ser explorada neste trabalho.

\subsection{Pronomes modificados ou quantificados}

Pronomes modificados em português sempre aparecem na forma nominativa, mesmo quando se encontram em posição de complemento:

(26) O João conhece o meu verdadeiro eu.

(27) O Rui não suporta eu lingüista.

(28) O Pedro encontrou nós três ontem.

De novo, estamos diante de exemplos em que o constituinte em que se encontra o pronome na forma nominativa está em um contexto de atribuição de Caso acusativo: são todos complementos de verbos transitivos. Como nos exemplos com constituintes coordenados, é possível que o licenciamento sintático de Caso acusativo se aplique ao núcleo desses constituintes e que, por alguma razão, em português brasileiro, esse Caso não se espalhe para outros constituintes dentro da projeção desse núcleo. No caso de (26), o núcleo $\mathrm{D}^{0}, o$, é que deve receber o Caso acusativo; em (27), o Caso acusativo deve ser atribuído ao núcleo da small clause, ${ }^{11}$ lingüista; e, em (28), o quantificador trêsé que deve receber o Caso acusativo. ${ }^{12}$ Entretanto, como já dito anteriormente, essa é uma questão 
complexa, que merece um estudo mais detalhado e está fora do âmbito deste artigo.

\subsection{Resumo do item 3}

Os fatos apresentados neste item mostram que:

(i) é necessário postularmos um Caso default, que se aplica a sintagmas nominais que não são sintaticamente licenciados para Caso;

(ii) em português do Brasil, o Caso defaulté o Caso nominativo;

(iii) em português do Brasil, alguns dos contextos em que sintagmas nominais não têm Caso licenciado na sintaxe e, por isso, são marcados com o Caso nominativo default são:

- sintagmas nominais e posição de deslocamento à esquerda ou à direita;

- sintagmas nominais em contextos em que um possível atribuidor de Caso está elidido;

- sintagmas nominais em posição de especificador ou complemento de uma projeção de coordenação;

- pronomes modificados ou quantificados.

A seguir, investigo a possibilidade de tratar o Caso do complemento dos verbos inacusativos do português do Brasil como uma outra instanciação de Caso default.

\section{O CASO DOS COMPLEMENTOS DOS VERBOS INACUSATIVOS}

O Programa Minimalista captura a impossibilidade de verbos inacusativos atribuírem Caso acusativo a seus complementos, sugerindo que sentenças construídas com esses verbos não têm a projeção de $v$, que é o núcleo que licencia, na sintaxe, o Caso acusativo de sentenças construídas com verbos transitivos. Desde que os verbos inacusativos começaram a ser estudados por Perlmutter (1978) e 
Burzio (1986), uma das questões-chave das pesquisas relacionadas a eles tem sido a de se estabelecer o Caso do único argumento desses verbos.

Retomemos o exemplo (1):

(29) a) Chegaram várias pessoas na festa.

b) Chegou várias pessoas na festa.

Como se vê, em português brasileiro, verbos inacusativos podem ou não exibir concordância com seu argumento interno, quando ele aparece em posição pós-verbal. Nos termos do Programa Minimalista, em sua versão de 1995, para dar conta da sintaxe de uma sentença como (29)a, em que há concordância entre o verbo e seu complemento, seria necessário postular-se a existência de um expletivo nulo do tipo there, que ocuparia a posição de Spec TP, checando os traços D-forte de T. Os traços $\phi$ e os traços de Caso nominativo do argumento interno do verbo subiriam no componente coberto, para serem checados contra os traços $\phi$ e os traços de Caso de T.

Entretanto, para explicar a sintaxe de uma sentença como (29)b, em que não há concordância entre o verbo e seu complemento, o expletivo a ocupar a posição de Spec TP não poderia ser do tipo there. Seria necessário que ele fosse do tipo it. Esse expletivo, em Spec TP, checaria tanto os traços D-forte de T, como também seus traços $\phi$ e seus traços de Caso nominativo. Isso nos deixaria sem explicação para o Caso do complemento do verbo.

Viotti (1999), tratando de sentenças existenciais, de sentenças construídas com ergativos e de sentenças com verbos na voz passiva, propõe uma solução para essa questão, evitando o recurso ao expletivo nulo. Em Viotti (2003a, b), essa proposta é revista à luz das modificações ao Programa Minimalista, introduzidas em Chomsky (1998, 1999). Nesses trabalhos, a autora propõe que a gramática de uma sentença como (29)a é a seguinte. Primeiramente, trata-se de uma sentença de foco apresentacional e, por isso, deve ser nucleada por uma categoria $\mathrm{C}$ diferente da categoria $\mathrm{C}$ que nucleia sentenças declarativas. Essa categoria $\mathrm{C}$ que tem traços de foco apresentacional 
s-seleciona uma categoria T defectiva. Essa categoria T é defectiva pelo fato de não permitir traços EPP. Entretanto, ela tem um conjunto completo de traços $\phi$ não-interpretáveis. ${ }^{13}$ Esses traços tornam a categoria T ativa para entrar em uma relação de Agree e precisam ser apagados. O DP complemento do verbo, por sua vez, tem traços $\phi$ interpretáveis, o que o torna um gol legítimo para entrar na relação de Agree com T. Ao mesmo tempo, esse DP tem traços de Caso nãointerpretáveis, que o tornam ativo para entrar em relação de Agree e que precisam ser apagados. Agree, então, se estabelece entre T e o DP complemento do verbo, os traços não-interpretáveis dos dois são apagados, a concordância se manifesta no verbo, e o DP é valorado com Caso nominativo.

Diferentemente, a gramática das sentenças em (29)b tem a seguinte forma. Da mesma maneira que no caso das sentenças em (29)a, essas sentenças são nucleadas por uma categoria C de foco apresentacional. Essa categoria s-seleciona uma categoria T defectiva, não só porque ela não permite traços EPP, mas também porque ela não tem um conjunto de traços $\phi$ não-interpretáveis, visto que não há concordância entre o verbo e seu argumento. Não tendo traços $\phi$, T não está ativo para atuar como sonda e entrar em uma relação de Agree. Conseqüentemente, se o DP complemento do verbo tiver traços não-interpretáveis de Caso estrutural, esses traços não vão poder ser checados e apagados, porque não existe nenhuma categoria funcional com traços $\phi$ não-interpretáveis compatíveis com os do DP e que possa entrar em uma relação de Agree com ele. Isso faria com que a sentença não convergisse, contrariamente aos fatos.

Para explicar a convergência de sentenças como (29)b, gostaria de sugerir que, em casos como esse, o DP complemento do verbo entra na derivação sem Caso. Na sintaxe, ele passa incólume. Afinal, ele está em uma configuração em que não há como ocorrer um licenciamento sintático de Caso. Entretanto, depois de spell-out, no componente morfológico, ele é marcado com Caso nominativo default. Vejam que essa possibilidade se evidencia nas sentenças apresentadas entre (30) e (34), possíveis no português brasileiro coloquial: 
(30) Chegou eu primeiro, depois ele.

(31) Dos gêmeos, eu sou a mais velha: nasceu eu, logo depois nasceu o Juca.

(32) Faltou eu na foto de celebração das bodas de ouro de meus pais.

(33) No vídeo da festa, aparece eu, aparece a Ana, mas nunca o João.

(34) Naquele empurra-empurra, foi uma confusão: caiu eu, caiu meus irmãos, caiu todo o mundo.

Nessas sentenças, o verbo aparece na $3^{\mathrm{a}}$ pessoa do singular, e não na $1^{\mathfrak{a}}$ pessoa do singular, não concordando, portanto, com seu argumento $e u$. Isso indica que estamos diante de uma categoria T sem traços $\phi$. Sem esses traços, T não está ativo para entrar em uma relação de Agree com nenhum DP. Se T não pode entrar em relação de Agree com o DP complemento do verbo, e se esses verbos não têm uma projeção $v$ (como sugere o Programa Minimalista), não há meios de o Caso do DP complemento ser licenciado na sintaxe. Conseqüentemente, o Caso nominativo exibido pelos pronomes em posição pós-verbal não pode ser um Caso que tenha sido licenciado sintaticamente. Só pode ser um Caso default. Esse DP deve ter entrado na derivação sem traços de Caso. Em conseqüência, não precisou passar por nenhuma operação de apagamento de traço de Caso na sintaxe. Ao chegar ao componente morfológico, recebeu as marcas de Caso default, que, como já visto, em português, é o Caso nominativo.

A situação seria diferente se houvesse concordância nos verbos. Sentenças como as entre (35) e (39) teriam Caso nominativo checado na sintaxe, nos termos da explicação que foi dada para a sentença (29)a.

(35) Cheguei eu primeiro, depois ele.

(36) Dos gêmeos, eu sou a mais velha: nasci eu, logo depois nasceu o Juca.

(37) Faltei eu na foto de celebração das bodas de ouro de meus pais.

(38) Naquele filme, apareço eu, aparece a Ana, mas nunca o João. 
(39) Naquele empurra-empurra, foi uma confusão: caí eu, caíram meus irmãos, caiu todo o mundo.

A categoria T dessas sentenças teria um conjunto completo de traços $\phi$ não-interpretáveis, que a tornariam ativa para estabelecer uma relação de Agree. Por serem não-interpretáveis, esses traços precisariam ser apagados na sintaxe. Por outro lado, o DP complemento do verbo tem traços $\phi$ interpretáveis, constituindo um gol legítimo para entrar em uma relação de Agree com T. Esse DP tem também traços de Caso não-interpretáveis, que precisam ser apagados. São esses traços que o tornam ativo para entrar em uma relação de Agree. Uma vez estabelecida essa relação entre T e o DP, os traços $\phi$ não-interpretáveis de T e os traços de Caso não-interpretáveis do DP são apagados, a concordância se manifesta no verbo, e o DP é valorado com Caso nominativo.

Portanto, a proposta deste trabalho é a de que, nas sentenças construídas com verbos inacusativos, o Caso atribuído ao DP complemento do verbo é sempre o Caso nominativo. Existe, no entanto, uma diferença entre as sentenças cujo verbo concorda com o DP complemento e aquelas em que o verbo não exibe marcas de concordância com seu complemento. Apenas nessas é que o Caso do DP complemento é uma instância do Caso default. Nas primeiras, o Caso nominativo do DP complemento é uma instância de Caso licenciado na derivação sintática.

É interessante observar que é crucial que as sentenças entre (29) e (39) não tenham uma projeção de $v$, como, de resto, sugere o Programa Minimalista para as sentenças construídas com verbos inacusativos. Se essa projeção existir e se tiver um conjunto completo de traços $\phi$, o núcleo $v$ vai ser uma sonda mais próxima para entrar em uma relação de Agree com os DPs das sentenças. Não poderíamos explicar, assim, como é que, em (29)a e nas sentenças entre (35) e (39), acontece a concordância do verbo com seu argumento interno. Por fim, a presença do núcleo $v$, atribuidor de Caso acusativo, impediria que os DPs complementos das sentenças em (29)b e das sentenças entre (30) e (34) pudessem receber Caso default no 
componente morfológico. Afinal, nos termos da proposta de Schütze, para que um DP possa ter Caso default, é crucial que nada haja na sintaxe que possa atribuir a ele um outro tipo de Caso.

\section{CONCLUSÃO}

Neste artigo, mostrei vários contextos do português brasileiro em que DPs são marcados com o Caso default. Esses contextos são aqueles nos quais os constituintes nominais ocupam uma posição sintática em que o licenciamento de Caso não poderia ter ocorrido, ou aqueles em que os DPs aparecem com marcas de Caso nominativo, contrariamente ao que se esperaria. Assim sendo, os dados do português brasileiro corroboram a idéia de Schütze (2002), segundo a qual o Caso default é atribuído, no componente morfológico, aos DPs que entraram na sintaxe sem qualquer traço de Caso.

Mostrei, ainda, que nas sentenças construídas com verbos inacusativos em que não há concordância entre o verbo e o DP em posição pós-verbal, o Caso exibido por esse DP é uma instância de Caso nominativo default. Diferentemente, nas sentenças construídas com verbos inacusativos em que o verbo concorda com o DP complemento, esses DPs são marcados com Caso nominativo sintaticamente licenciado.

\section{NOTAS}

${ }^{1}$ Neste trabalho, mantenho as siglas dos constituintes sintáticos correspondentes a seus rótulos em inglês: DP para sintagmas introduzidos por um determinante; NP para sintagmas nominais; VP para sintagmas verbais, TP para o sintagma de flexão de tempo; $v \mathrm{P}$ para o sintagma nucleado pelo verbo leve, e assim por diante.

${ }^{2}$ Ver Viotti (1999) e Viotti (2000) para uma crítica a essas propostas.

${ }^{3}$ Cf. Chomsky (1995).

${ }^{4}$ Optei por construir os exemplos sempre usando o pronome da 1a. pessoa do singular (ou eventualmente do plural), porque a distinção entre suas formas nominativa, acusativa e oblíqua é mais nítida.

${ }^{5}$ Ver Ross (1967). 
${ }^{6}$ Apesar de o DP a única professora disponível não apresentar marcas morfológicas de Caso acusativo, sabe-se que esse DP, sendo complemento do verbo, precisa checar seus traços de Caso contra os traços de Caso do verbo. Esse tipo de checagem é associado ao Caso acusativo. Tanto é assim que, se o DP for substituído por um pronome, esse pronome vai aparecer na forma acusativa: $O$ jornalistame entrevistou.

${ }^{7}$ De fato, nos termos da gramática normativa do inglês, as sentenças (21) e (22) deveriam ter a forma We and they are going to rumble tonight e She and we have been friends for ages.

${ }^{8}$ As sentenças (c) e (d) de (23) são aceitas por pessoas que seguem os preceitos da gramática normativa e que têm um alto nível de escolarização.

${ }^{9}$ As sentenças (24) são do dialeto gaúcho. As sentenças (c) e (d) são aceitas pelos falantes que têm alto nível de escolarização e fazem questão de seguir os preceitos da gramática normativa. Agradeço os exemplos e a informação a César Verdi e a Maria do Carmo Favaro.

${ }^{10}$ Agradeço os exemplos a Mirta Groppi.

${ }^{11}$ Estou assumindo que a estrutura da sentença (27) apresenta uma small clause na posição de complemento do verbo suportar, que tem por núcleo o N0 lingüista. A estrutura seria semelhante às de sentenças construídas com o verbo considerar e, tanto quanto elas, também pode ser considerada uma construção de ECM, em que o verbo atribui Caso acusativo ao constituinte na posição de Spec da small clause. (Cf. O Rui não me suporta lingüista). Mesmo assim, a sentença (27) mostra que existe a possibilidade de o verbo da sentença matriz não atribuir Caso acusativo a constituintes dentro da small clause, o que é um problema para a noção de Barreira.

12 Estou assumindo, sem qualquer discussão, que o complemento do verbo encontrar, em (28), é um QP nucleado por três, e que o pronome nós está na posição de especificador desse QP.

${ }^{13}$ É importante observar que, em um ponto do texto de 1999, Chomsky associa os traços EPP à f-completude, dizendo que categorias que têm um conjunto completo de traços f permitem traços EPP. A meu ver, o uso do termo permitir (allow, em inglês), possibilita a interpretação de que esses traços podem, mas não precisam, ser incorporados à categoria. Ao mesmo tempo, Chomsky sugere que, para que uma categoria funcional possa entrar em uma relação de Agree, ela precisa ser f-completa. Não é claro para mim se ela precisa ser f-completa com traços EPP, ou apenas f-completa por ter um conjunto completo de traços f. Aqui, estou assumindo essa segunda opção. 


\section{REFERÊNCIAS BIBLIOGRÁFICAS}

BELlETTI, A. The Case of unaccusatives. Linguistic Inquiry, n. 19, v. 1, p. 1-34, 1988.

BURZIO, L. Italian syntax. A government-binding approach. Dordrecht: Kluwer, 1986.

CHOMSKY, N. Lectures on government and binding. Dordrecht: Foris, 1981.

1986. Knowledge of language: its nature, origin and use. Nova York: Praeger, . The Minimalist Program. Cambridge, Mass: The MIT Press, 1995.

. Minimalist inquiries: The framework. MIT Occasional Papers in Linguistics, n. 15, p. 1-61, 1998.

Derivation by phase. Ms. MIT, 1999.

HALLE, M.; MARANTZ, A. Distributed morphology and the pieces of inflection. In: HALLE, K.; KEYSER, S. J. (Ed.). The view from building 20. Cambridge, Mass: MIT Press, 1993. p. 111-176.

PERLMUTTER, D. Impersonal passives and the unaccusative hypothesis. Berkeley Linguistc Society, n. IV, p. 157-189, 1978.

ROSS, J.R. Constraints on variables in syntax. 1967. Tese (Doutorado) - MIT. Publicada como Infinite Syntax. New Jersey: Ablex Publishing Corporation, 1986.

SCHÜTZE, C. On the nature of default case. Syntax, n. 4, v. 2, p. 205-234, 2002.

VIOTTI, E. A sintaxe das sentenças existenciais do português do Brasil. 1999. Tese (Doutorado) - Universidade de São Paulo.

- O Caso do sintagma nominal das sentenças existenciais. Fórum Lingüístico, Florianópolis, UFSC, n. 2, v. 1, p. 41-71, 2000.

. O EPP e a ordem VS: questionando a existência de expletivos nulos em português do Brasil. Ms., Universidade de São Paulo. Trabalho apresentado no III Congresso Internacional da ABRALIN, UFRJ, mar. 2003 a.

Revisitando a ordem VS do português brasileiro. Ms., Universidade de São Paulo. Trabalho apresentado no II Encuentro de Gramática Generativa, Buenos Aires, ago. 2003b. 